\title{
WHEN THREE BECOME TWO: DROSERA COALARA LINKS DROSERA CITRINA WITH DROSERA NIVEA
}

Thilo Alexander Krueger • Curtin University • Kent Street • Bentley • Perth • $6102 \cdot$ Western Australia・Australia・t.krueger@student.curtin.edu.au

AndREas FleischmanN • Botanische Staatssammlung München • Menzinger Strasse 67 - D-80638

Munich • Germany・fleischmann@bio.lmu.de

Keywords: taxonomy, Drosera sect. Bryastrum, pygmy Drosera, pollination ecology, Western Australia.

The pygmy sundews (Drosera section Bryastrum) are the second-largest group of Australian Drosera in terms of species number following the tuberous sundews. According to the latest revisions (Fleischmann et al. 2018; Robinson et al. 2018) they currently comprise 51 species in southwest Western Australia and six named natural hybrids (Lowrie 2014; Lowrie et al. 2017). Within the pygmy Drosera, a wide range of flower colors can be found, ranging from pure white, various shades of pink, metallic orange, and red to yellow colors, quite often with bi- or rarely even tricolored petals (Lowrie 1989; Robinson et al. 2018). The color combination of lime yellow petals with white base has thus far been considered to be unique to $D$. citrina (Lowrie \& Carlquist 1992; Lowrie 2014; Lowrie et al. 2017).

When first discovered in flower, Drosera citrina was described by Lowrie (1989; initially mistaken for D. rechingeri, until correctly classified by Lowrie \& Carlquist 1992) to be one of the most unique pygmy Drosera due to its striking flower color. The white-flowered $D$. nivea was denoted as its closest relative by Lowrie \& Carlquist (1992), but considered to represent a variety of $D$. citrina by Schlauer (1996) - the latter classification was not adopted by most Drosera taxonomists (e.g., Lowrie 1998, 2014; Lowrie et al. 2017; Fleischmann et al. 2018). With the description of $D$. coalara by Lowrie (2014), another closely related taxon was added

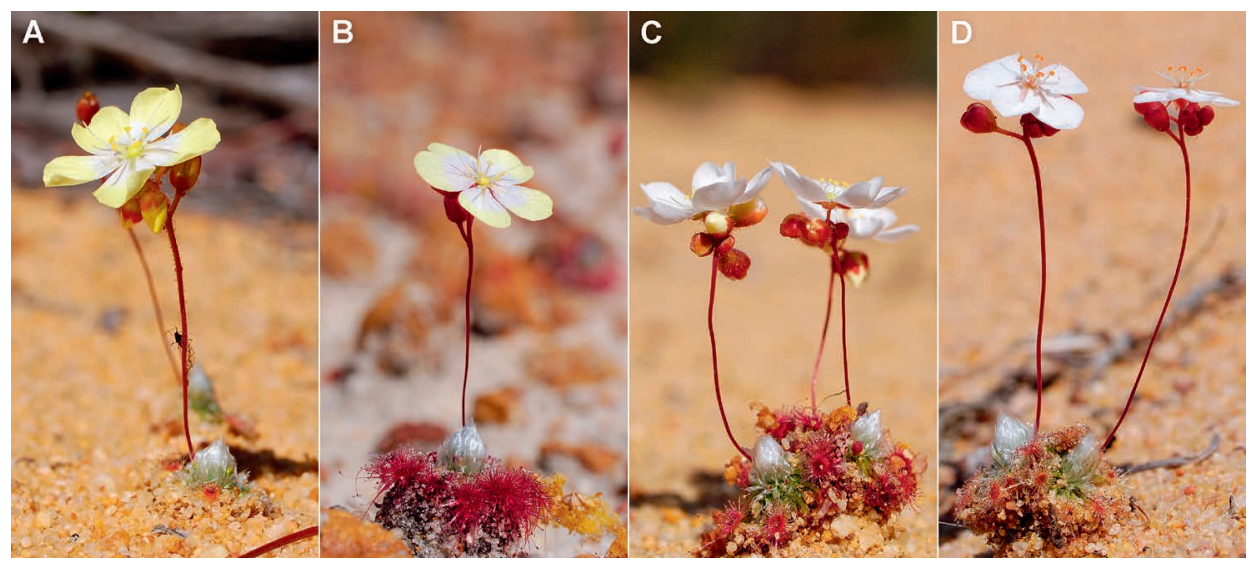

Figure 1: Comparison of Drosera citrina (Moora, A), D. coalara (from two different localities NE of Badgingarra, B, C), and D. nivea (Coorow, D). Photos: Thilo Krueger. 


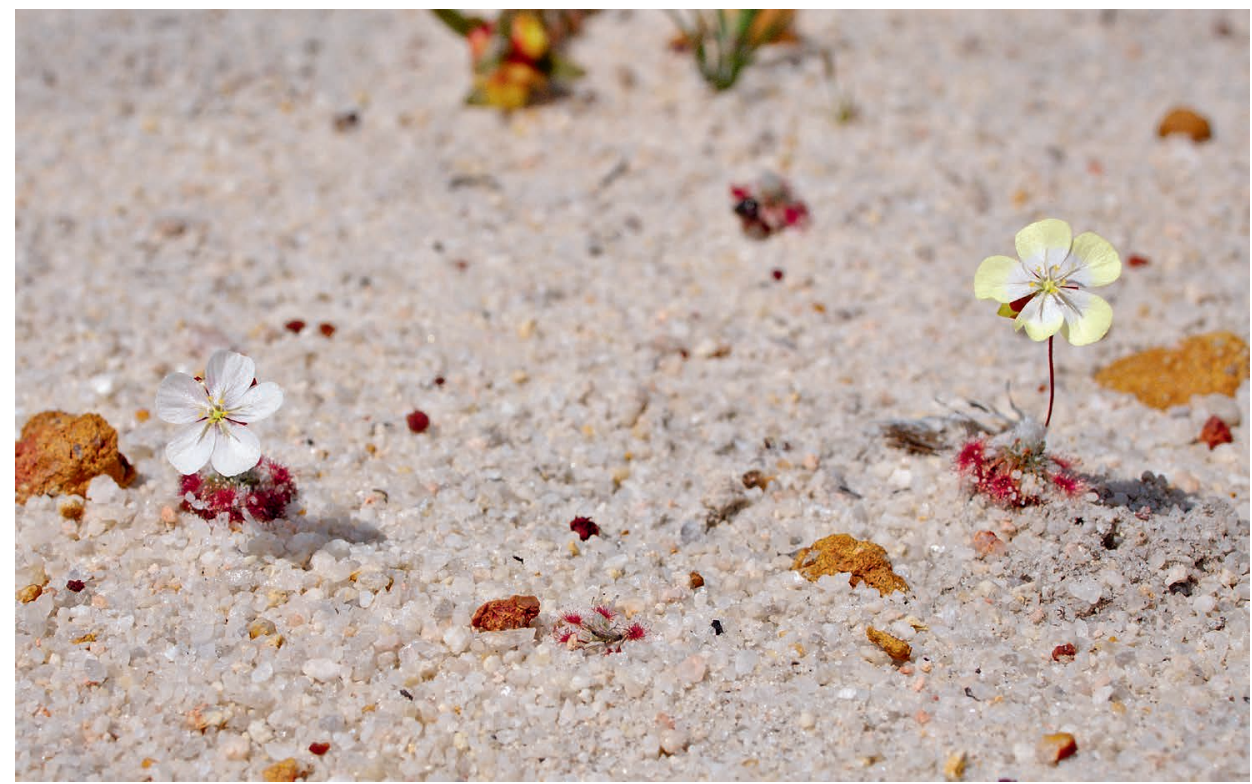

Figure 2: Sympatric occurrence of white- and yellow-flowered color morphs of Drosera coalara, northeast of Badgingarra, Western Australia. Photo: Thilo Krueger.

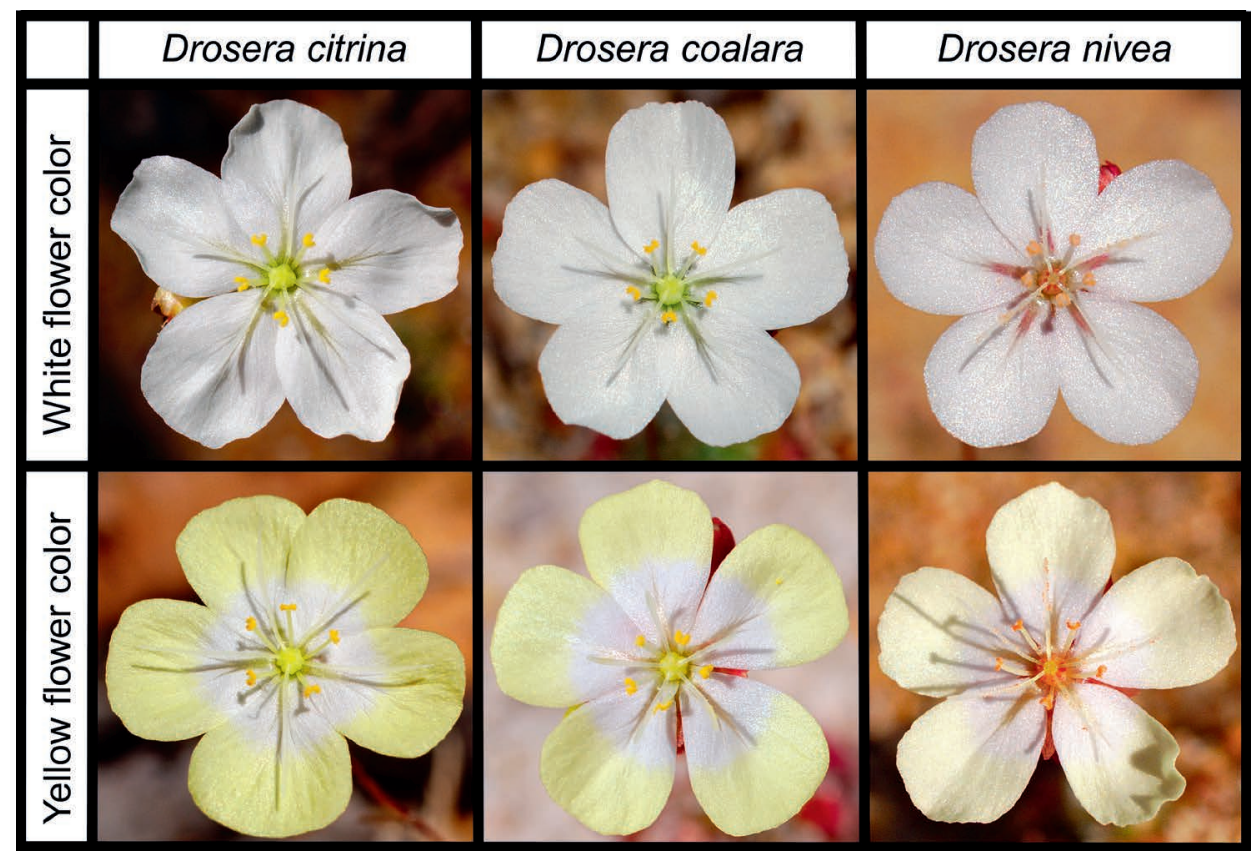

Figure 3: Comparison of white- and yellow-flowered color morphs of Drosera citrina, $D$. coalara, and D. nivea. Drosera citrina: both from Moora; D. coalara: both northeast of Badgingarra; D. nivea: top from Coorow, bottom southwest of Coorow. Photos: Thilo Krueger. 
to this affinity of species from the northern sand plains of southwest Western Australia (Fig. 1). At the time of its description, D. coalara was considered to be entirely white-flowered, just like $D$. nivea. Expeditions and field work by the first author in Western Australia revealed not only additional localities of the white-flowered variant of $D$. citrina (one of them already known to Lowrie (1989: 154): "An all-white-flower form of this species occurs at one location near Moora."), but also found white- and yellow-flowered D. coalara in mixed populations (Fig. 2), and surprisingly also yellow-flowered populations of $D$. nivea, hence all three species are now known to consist of both white- and yellow-flowered individuals (Fig. $3)$. Therefore, the diagnostic characters delimiting these three species were re-investigated in the light of the new populations and data discovered, and some characters such as stipule shape and flower number as described by Lowrie (2014) where examined on a wider range of specimens and populations (including the type localities for all three taxa, as well as the type specimens).

\section{Distribution and Habitats}

All three taxa are confined to the sand plains and heathlands between Coorow and Gingin in southwest Western Australia (Fig. 4). Drosera citrina only occurs in deep yellow sands in open Banksia forests (or rarely in heathland) on the Dandaragan Plateau between Moora and Gingin. It is currently known from ca. 10 populations (Fig. 4). White-flowered plants of D. citrina from near Moora were first reported by Lowrie (1989; erroneously as "D. rechingeri" at the time). Drosera nivea inhabits deep white to beige sands on sand-plains among low heath vegetation (Lowrie 1998, 2014), and it has been recorded from seven sites between the towns of Coorow and Watheroo (Fig. 3). In Lowrie (2014), the range of D. nivea was erroneously illustrated ca. $100 \mathrm{~km}$ to the east of its actual range. Drosera coalara was only known from two localities according to the original description, namely the type locality northeast of Badgingarra, and a small roadside population west of Mogumber, which is ca. $96 \mathrm{~km}$ distant to the south (Lowrie 2014). According to the authors of the present work, the Mogumber population reported by Lowrie likely represents white-flowered $D$. citrina due to their relatively long peduncles (curiously, the Mogumber site also has not been included in the species' range map by Lowrie 2014). This would leave only the locus classicus for D. coalara. In September 2019, the first author of this work discovered at least seven additional populations of $D$. coalara, most of which lie within the ca. $100 \mathrm{~km}$ diameter circle that was drawn around the type locality of $D$. coalara to illustrate the species' distribution in Lowrie (2014). Two of these populations were, however, found near Wannamal, more than $100 \mathrm{~km}$ south of the type locality. Drosera coalara grows in a wide range of different heathland habitats, including deep yellow, beige, and gray sands and even almost pure laterite (pers. obs; Lowrie 2014).

Drosera citrina and D. nivea show allopatric distribution (their ranges do not overlap, both species are separated geographically by ca. $50 \mathrm{~km}$ between the closest localities, Fig. 4), $D$. coalara is parapatric with $D$. nivea (the ranges touch in a narrow border zone but do not overlap much) and sympatric distribution with $D$. citrina. The ranges of all three species seem to represent a continuum (Fig. 4) - and it might be better to consider only two taxa, D. citrina in the south, $D$. nivea in the north, both mediated by transitional forms in-between, which have been described as $D$. coalara. In the range border zones, transitional forms occur (especially between $D$. nivea and $D$. coalara), but we did not observe sympatric occurrence of two or more of the above-mentioned three taxa. 


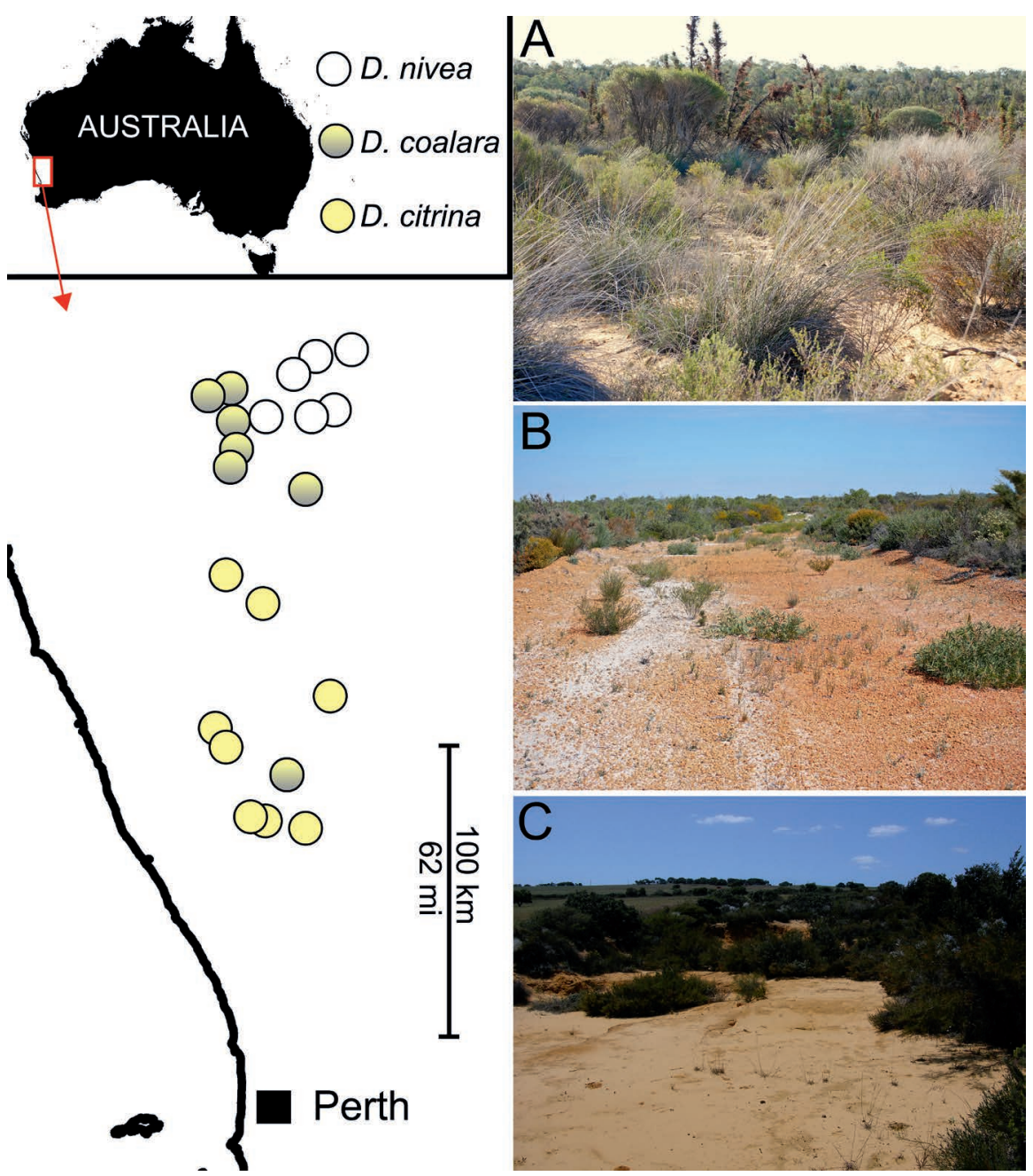

Figure 4: Distribution map based on Atlas of Living Australia (2019), Lowrie et al. (2017) and personal observations. All localities have been visited and confirmed by the authors of this work. Instead of three distinct species, the range can also be interpreted as a grade from $D$. citrina (predominantly yellow flowers) in the south to $D$. nivea (predominately white flowers) in the north, geographically and morphologically linked by $D$. coalara in the middle. Right: typical habitats of $D$. nivea (A, near Coorow), D. coalara ( $\mathrm{B}$, near Badgingarra) and $D$. citrina ( $C$, near Regans Ford). Photos: $A, B$ by Thilo Krueger, $C$ and Map by A. Fleischmann.

\section{Discussion}

Pollinators apparently do not distinguish between yellow- and white-flower color morphs - so why should botanists do so and call them different species?

Both yellow- and white-flowered individuals of $D$. coalara were found growing intermixed within the same population at all eight sites (including at the type locality) with varying percent- 

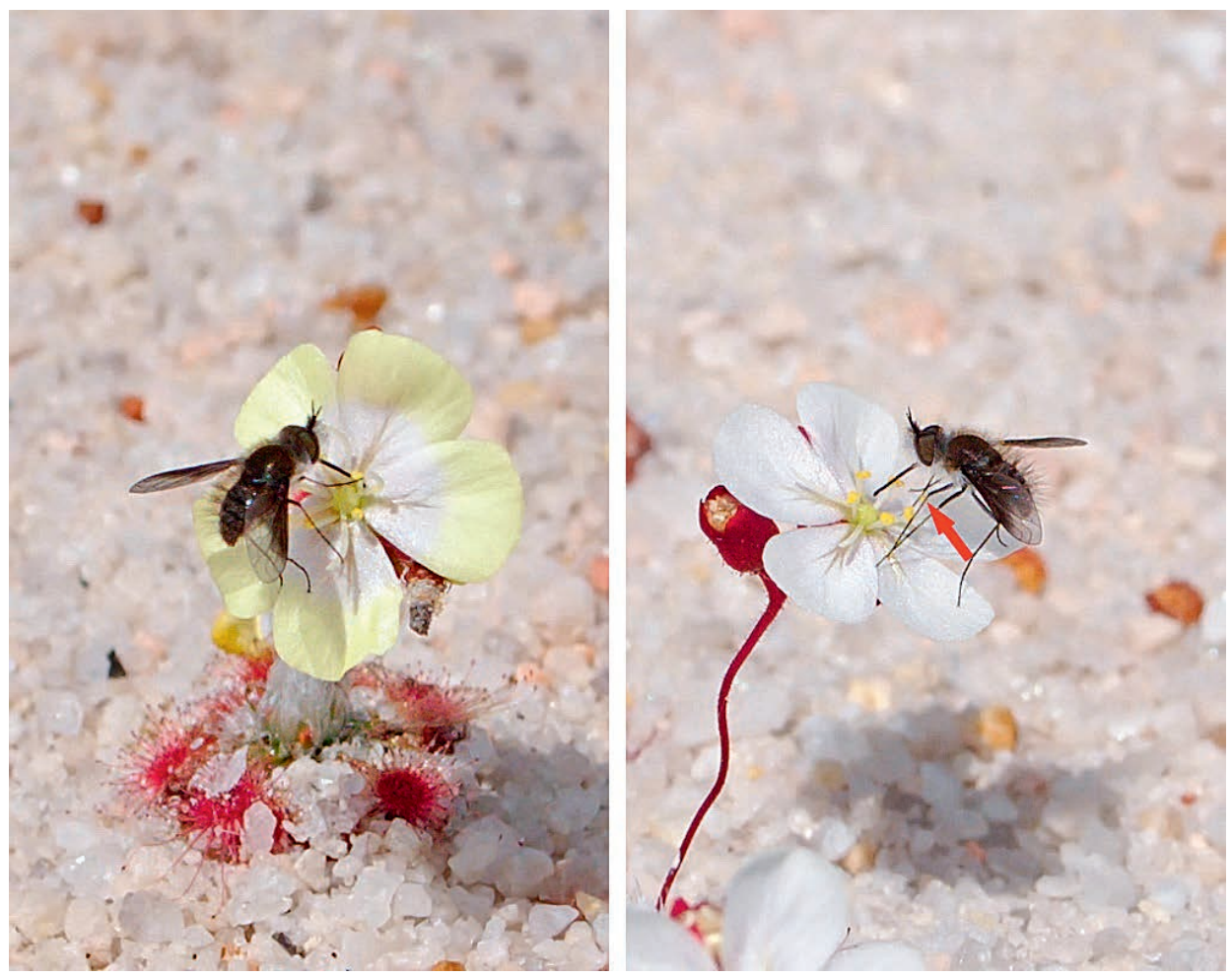

Figure 5: This white-flowered morph of $D$. coalara (right) was visited - and very likely also pollinated - by the same individual of the bee-fly Choristus (Diptera: Bombyliidae; genus identified by $\mathrm{X}$. Li) just four seconds after floral visit at a yellow morph (left). Note the Drosera pollen sticking to its left foreleg (arrow) from the first flower visit, enabling potential cross-pollination. Photos: Thilo Krueger.

age distributions of flower colors. Since all plants were flowering at the same time, and without any morphological difference of the plants apart from flower color (T. Krueger, pers. obs. 2019; Figs. 2, 5), these can be considered color morphs of one and the same species (not even worth being recognized taxonomically on forma rank). A pollinating bee-fly of the genus Choristus (family Bombyliidae; genus identified by X. Li) was observed by the first author to freely choose between the yellow and white flowers, without avoiding any of them, enabling cross-pollination (Fig. 5). Therefore, the mixed petal colors of $D$. coalara certainly belong to the same population's gene pool. Populations containing different color morphs are not unusual among flowering plants in general, and in Drosera in particular (e.g., most of the woolly sundews of D. sect. Lasiocephala occur in white- and pink-petalled individuals within the same population; pers. obs.). Intraspecific flower color variation (as observed by the human eye) was often found to be effectively invisible to specific pollinators in other plants, hence will persist in the population by genetic drift/neutral evolution (Paine et al. 2019).

Different small beetles have been observed by the authors as floral visitors of D. citrina and $D$. nivea, the latter species additionally shows signs of myophily (pers. obs.). Populations of $D$. citrina are predominately yellow-flowered, with occasional occurrence of white-flowered individuals among the populations. We did not find entirely white-flowered populations of D. citrina. In fact, 


\begin{tabular}{|c|c|c|c|}
\hline character & Drosera citrina & Drosera coalara & Drosera nivea \\
\hline peduncle length & $1.7-4.5 \mathrm{~cm}$ & $1.5-3.0 \mathrm{~cm}$ & $2.5-3.5 \mathrm{~cm}$ \\
\hline $\begin{array}{l}\text { number of flowers per } \\
\text { scape }\end{array}$ & $(4) 6-12(-16)$ & $(2) 3-6(-10)$ & $(2) 4-6(-10)$ \\
\hline petal color & $\begin{array}{l}\text { predominantly white } \\
\text { with yellow margin, } \\
\text { rarely pure white }\end{array}$ & $\begin{array}{l}\text { white or white with } \\
\text { yellow margin }\end{array}$ & $\begin{array}{l}\text { white, occasionally } \\
\text { white with pale } \\
\text { yellow (cream) } \\
\text { margin }\end{array}$ \\
\hline ovary color & yellowish-green & yellowish-green & pale red, rarely green \\
\hline pollen color & yellow & yellow & orange \\
\hline habitat & $\begin{array}{l}\text { yellow sand on } \\
\text { heathland }\end{array}$ & $\begin{array}{l}\text { yellow, beige or gray } \\
\text { sand, rarely laterite }\end{array}$ & $\begin{array}{l}\text { deep beige sands } \\
\text { on sand plains and } \\
\text { heathland }\end{array}$ \\
\hline
\end{tabular}

Drosera citrina Lowrie \& Carlquist, Phytologia 73(2): 99 (1992)

=Drosera rechingeri auct. non A.Strid, Carniv. Pl. Austral. 2: 154-157, xviii, xxxiv (1989).

=Drosera chrysochila Schlauer, Palmengarten 1992(3): 190 (1992).

=Drosera coalara Lowrie \& Conran, Carniv. Pl. Austral. Magnum Opus 3: 1269 (2014), syn. nov.

Drosera nivea Lowrie \& Carlquist, Phytologia 73(2): 104 (1992)

三Drosera citrina var. nivea (Lowrie \& Carlquist) Schlauer, Carniv. Pl. Newslett. 25(3): 72 (1996).

the white-flowered forms were extremely rare within the populations. The first author observed less than 10 white-flowered D. citrina amongst tens of thousands of yellow-flowered plants at a population near Moora. While most populations of $D$. nivea are predominantly white-flowered, intermixed and even purely yellow-flowered populations have been found by the first author.

\section{Three species, two, or a single variable one?}

Given the new data on variation and range overlap of the three taxa, the question arises how to best classify them - especially in the case of $D$. citrina and $D$. nivea. Infraspecific classification might be more appropriate in this case than two separate species. Schlauer (1996) suggested to distinguish the two taxa on variety rank - however, in his concept that would suggest sympatry (which has never been observed so far), and so the rank of subspecies (i.e., allopatric distribution) might be more appropriate. However, in the present work, we distinguish both taxa on species rank, with D. coalara treated as conspecific with $D$. citrina. We do so because typical plants of $D$. citrina and $D$. nivea can still be reliably separated based on habitat, distribution range, and few morphological characters (see also Table 1).

Lowrie and Conran (1992) and Lowrie $(1998,2014)$ consider the pedicel length to be a key character to delineate $D$. citrina from $D$. nivea (pedicel length $2.5-3.0 \mathrm{~mm}$ in $D$. citrina vs. 1.5-2.0 $\mathrm{mm}$ in $D$. nivea). Although $D$. nivea at its type population near Coorow has relatively longer pedicels than $D$. citrina from the southern part of its range, in a greater picture, the pedicel length of all known populations (including D. coalara: pedicel length 1.0-1.5 mm sensu Lowrie 2014) shows 


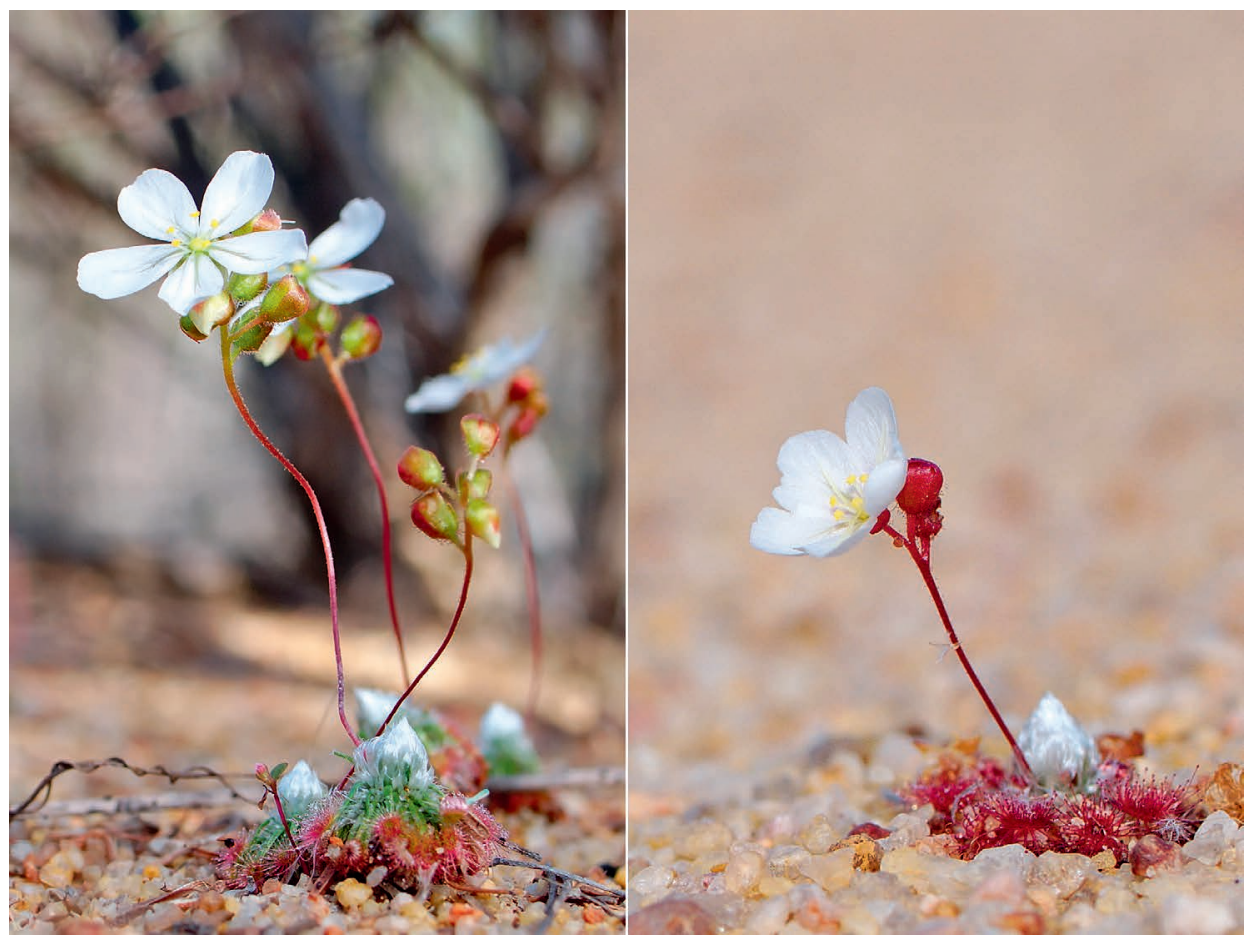

Figure 6: The peduncle and also pedicel length of $D$. coalara is extremely variable, even within the same population. The left and the right individuals were found less than $10 \mathrm{~m}$ apart, the one with shorter scapes at an area much more exposed to full sun. Photos: Thilo Krueger.

much variation and size overlap (Figs. 1,6). Therefore, we do not consider this character to be of taxonomic value to tell apart these species.

Drosera nivea often has notably longer peduncles than D. coalara and D. citrina (pers. obs.), however especially the latter has more flowers (up to 16, compared to 4-6(rarely up to 10) flowers in D. nivea; Lowrie 2014; however, the total number of flowers per scape in D. citrina has some geographic bias, with populations in the south bearing more flowers per scape, often 10-14, compared to mostly 6-8 flowers in northern populations), so that the total height/length of the flower scapes is similar in both species. However, both species frequently develop a second inflorescence, which is shorter in height and fewer-flowered - hence distinguishing features given here in Table 1 are based on the season's primary inflorescence. Drosera coalara generally produces the shortest peduncles of the three species (Fig. 1), although peduncle length is quite variable in that taxon (even within the same population). Some individuals were observed to produce relatively long scapes, and hence closely resemble $D$. nivea except for ovary and pollen color (compare Fig. 1D with Fig. 6 left), while less than $10 \mathrm{~m}$ away plants with much shorter peduncles occurred (Fig. 6). Notably, individuals growing in more exposed parts of the habitat generally produced shorter and more reddish peduncles.

Lowrie (2014) describes upward-curved styles as a diagnostic feature of $D$. coalara (in contrast to the horizontally spread styles of $D$. citrina and $D$. nivea). However, horizontally spread styles 


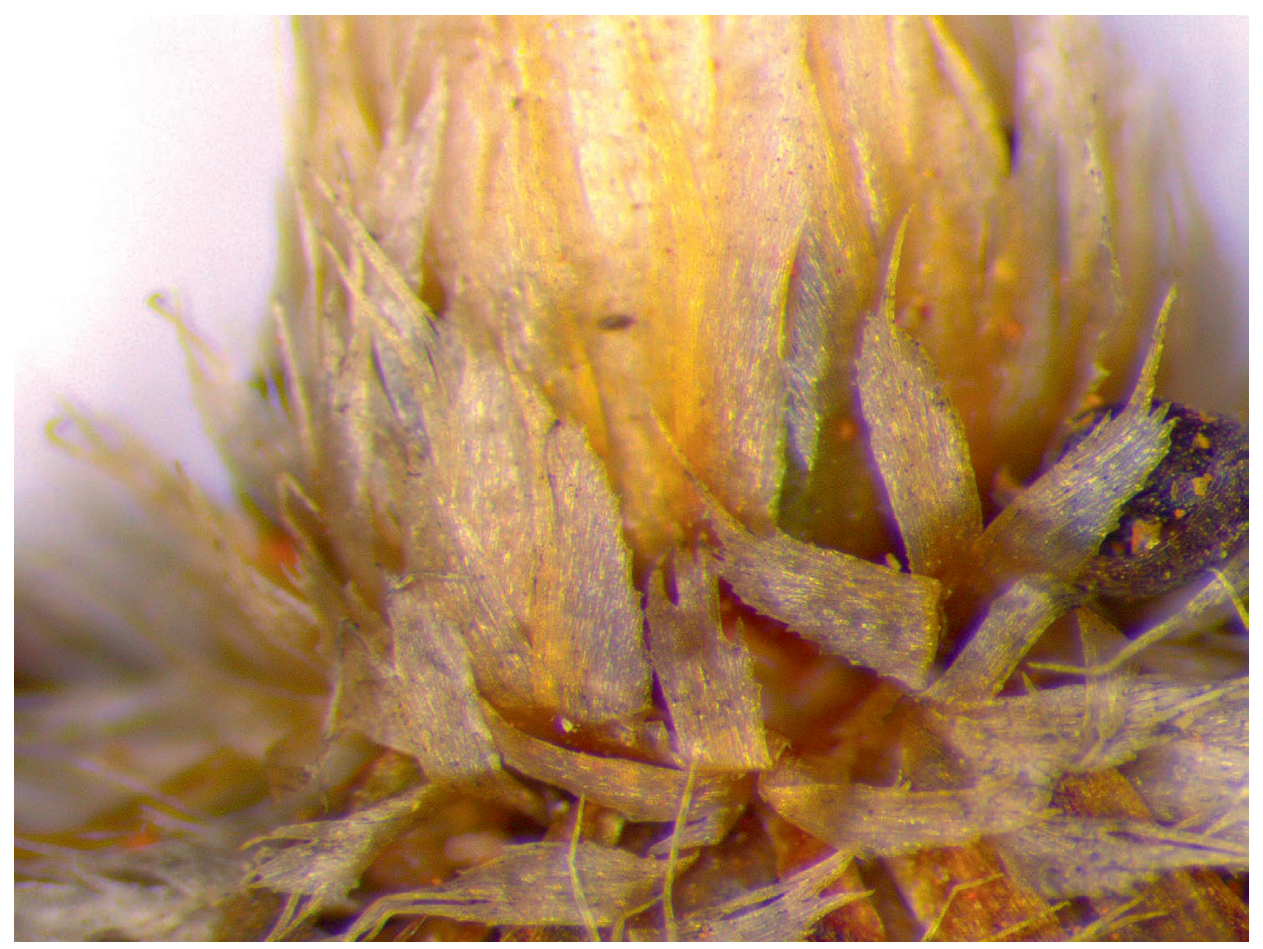

Figure 7: Close-up of the stipules from the type material of D. coalara (MEL2425943; isotype). Photo: Alastair Robinson.

(identical to those of the other two species) were observed in all populations of D. coalara studied (including at the locus classicus), and such are also pictured on the majority of habitat photographs of the species in Lowrie (2014: 373 figs. A, C \& F). Only a single photograph in Lowrie (2014: 373 fig. D) depicts upward-curved styles. The first author occasionally observed upward-curved styles in a few individuals in any population of $D$. coalara, $D$. citrina, or $D$. nivea visited, often in freshly opened or senescent flowers. Hence this might not represent a stable feature, but rather a transitional stage during anthesis (see Back Cover).

The shape of the dome-shaped stipule bud (especially during dormancy) has been used by Lowrie (2014) as a further character to delimitate D. citrina from D. nivea (and D. coalara). Indeed, D. citrina usually has a much broader, smoother stipule bud compared to the more narrow, ovoid and bristly appearance of the stipule buds of $D$. coalara and $D$. nivea. However, this feature was not observed to be consistent as within each population of $D$. citrina some individuals produced the same type of stipule bud as the other two taxa. Likewise, some plants of D. coalara (even at its type locality) possessed a broad and smooth stipule bud extremely similar to D. citrina.

Lowrie (2014) highlighted the stipules of $D$. coalara to be notably different from those of $D$. citrina and $D$. nivea, with the former having stipules with very short apical laciniae, while those of the other two species are long-laciniate. However, the present authors have found stipules of $D$. coalara, including those from the type material (Fig. 7), not to match those illustrated in Lowrie (2014: 370-373). Instead they are identical to those of D. citrina and D. nivea - these three taxa cannot be distinguished based on stipule characters (Fig. 8), in contrast to the diagnosis given by 


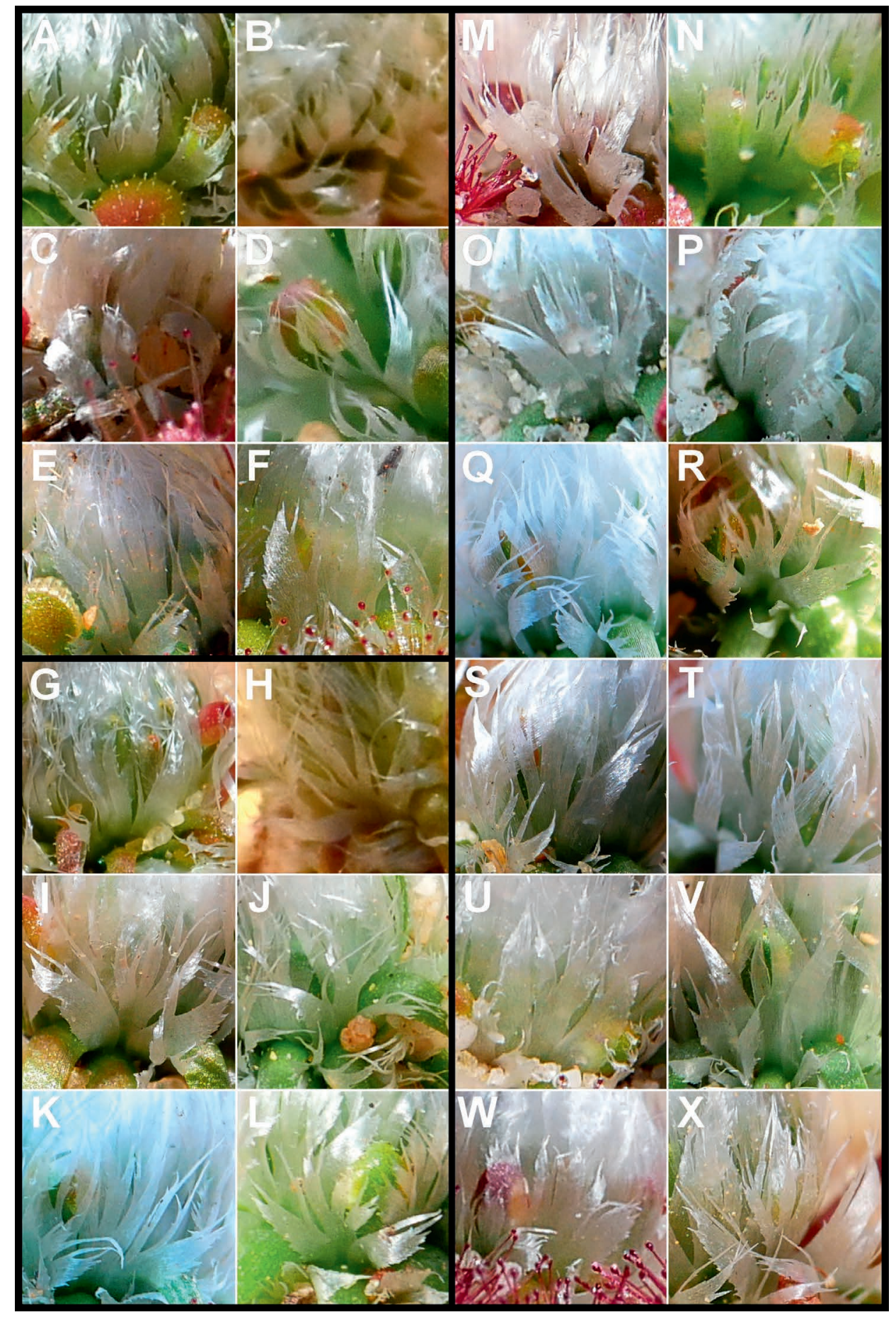


Lowrie (2014). Additionally, the shape and size of the stipules in most pygmy Drosera varies with the seasonal growth cycle, with stipules of dormant stipule buds or during gemmae production often being notably different from those produced during active growth (pers. obs.) - hence it is critical to document the stipules of the entire growth cycle, and compare among different populations of the same species, to get a clear picture of the individual ontogenetic and the intraspecific variation. Finally, the characters of petiole shape in section and lamina outline as mentioned by Lowrie (2014: petiole in section lenticulate and lamina more or less orbicular in D. coalara; petiole in section oblong with longitudinal ridges and lamina orbicular or elliptic in D. citrina; petiole in section depressed obovoid and lamina elliptic in $D$. nivea) were found to be variable within a population and even a given individual depending on the respective leaves and time observed (pers. obs.), and generally identical in all three taxa at the same developmental stage of the seasonal growth cycle. This leaves no reliable vegetative character to tell apart $D$. citrina from $D$. nivea in sterile specimens, both can only be distinguished with certainty based on flower characters (see above and Table 1).

As all major morphological characters of $D$. coalara fall within the observed variation of $D$. citrina (see Table 1), we consider both taxa to be conspecific, with D. coalara representing a heterotypic synonym of $D$. citrina. There is also significant morphological overlap with $D$. nivea, but that species can be distinguished from $D$. citrina (including $D$. coalara and regardless of color morph) by its orange pollen ( $v s$. yellow pollen in $D$. citrina/D. coalara), usually longer peduncles and a mostly pale red ovary (vs. ovary always greenish-yellow; see Table 1 and Figs. 1, 3). In cultivation, if kept under identical growing conditions, $D$. nivea (plants from near Coorow are most frequently grown) also flowers notably earlier than $D$. citrina, usually 1-2 months ahead, leaving little or no overlap in flowering time, with $D$. citrina usually opening its first flowers when all those on the scapes of $D$. nivea are already spent (pers. obs.). However, their phenology in the wild does not differ as much as in cultivation, and all three taxa have been observed in full bloom in Western Australia by the first author in mid-September 2019. Drosera nivea from near the type locality and D. citrina from Moora both had opened their third or fourth (on average) sequential flower on the scape at the time (T. Krueger, pers. obs.). However, at least the more southern populations of D. citrina (e.g. those near Gingin) appear to exhibit a more extended anthesis time, flowering at least until mid-October and also bear considerably more flowers per inflorescence (pers. obs.).

Figure 8: (facing page): Comparative close-up images of stipules from different populations of $D$. citrina $(A-F), D$. nivea $(G-L)$, and $D$. coalara $(M-X)$. Stipule shape is very variable in all three taxa and it is thus impossible to delineate species based on this feature. A: D. citrina, Gingin, October 2014; B: D. citrina, Gingin, October 2014; C: D. citrina, Mogumber, September 2019; D: D. citrina, Moora, June 2019; E: D. citrina, Moora, September 2019; F: D. citrina, Moora, September 2019; G: D. nivea, Coorow 1, October 2014; H: D. nivea, Coorow 1, October 2014; I: D. nivea, Coorow 2, September 2019; J: D. nivea, Coorow 2, September 2019; K: D. nivea, SW of Coorow, September 2019; L: D. nivea, SW of Coorow, September 2019; M: D. coalara, locus classicus, June 2019; N: D. coalara, locus classicus, June 2019; O: D. coalara, locus classicus, September 2019; P: D. coalara, locus classicus, September 2019; Q: D. coalara, Locality 1, September 2019; R: D. coalara, Locality 1, September 2019; S: D. coalara, Locality 1, September 2019; T: D. coalara, Locality 1, September 2019; U: D. coalara, Locality 2, September 2019; V: D. coalara, Locality 3, September 2019; W: D. coalara, Locality 4, September 2019; X: D. coalara, Locality 5, September 2019. All photos by Thilo Krueger. 
Acknowledgments: Xuankun Li (Australian National Insect Collection, Canberra) for identification of the bombyliid pollinator. Jan Schlauer, Allen Lowrie, Richard Nunn, Greg Bourke, Manfred Meisterl, and Alastair Robinson for fruitful discussions on Australian Drosera taxonomy over the past decades, the latter additionally for providing herbarium photographs from MEL. Jan Schlauer is thanked for helpful comments on the manuscript.

\section{References}

Atlas of Living Australia 2019. www.ala.org.au [accessed 02 Oct 2019]

Fleischmann, A., Cross, A.T., Gibson, R., Gonella, P.M., and Dixon, K.W. 2018. Systematics and evolution of Droseraceae. In: Ellison, A.M. \& Adamec, L. (eds.): Carnivorous Plants: Physiology, Ecology, and Evolution. Oxford University Press, pp. 45-57.

Lowrie, A. 1989. Carnivorous Plants of Australia 2. University of Western Australia Press, Nedlands.

Lowrie, A. 1998. Carnivorous Plants of Australia 3. University of Western Australia Press, Nedlands.

Lowrie, A. 2014. Carnivorous Plants of Australia Magnum Opus. Redfern Natural History, Dorset. 3 Volumes.

Lowrie, A., and Carlquist, S. 1992. Eight new taxa of Drosera from Australia. Phytologia 73: 98116.

Lowrie, A., Robinson, A., Nunn, R., Rice, B., Bourke, G., Gibson, R., McPherson, S., and Fleischmann, A. 2017. Drosera of the World 2, Oceania, Asia, Europe, North America. Redfern Natural History, Dorset. 554 pp.

Paine, K.C., White, T.E., and Whitney, K.D. 2019. Intraspecific floral color variation as perceived by pollinators and non-pollinators: evidence for pollinator-imposed constraints? Evolutionary Ecology 33: 461-479.

Robinson, A.S., Cross, A.T., Meisterl, M.E., and Fleischmann, A. 2018. A new pygmy sundew, Drosera albonotata (Droseraceae), from the western Wheatbelt and an updated diagnostic key to the orange-flowered pygmy Drosera of Western Australia. Phytotaxa 346: 221-236.

Schlauer, J. 1996. A dichotomous key to the genus Drosera L. (Droseraceae). Carnivorous Plant Newsletter 25: 67-88.

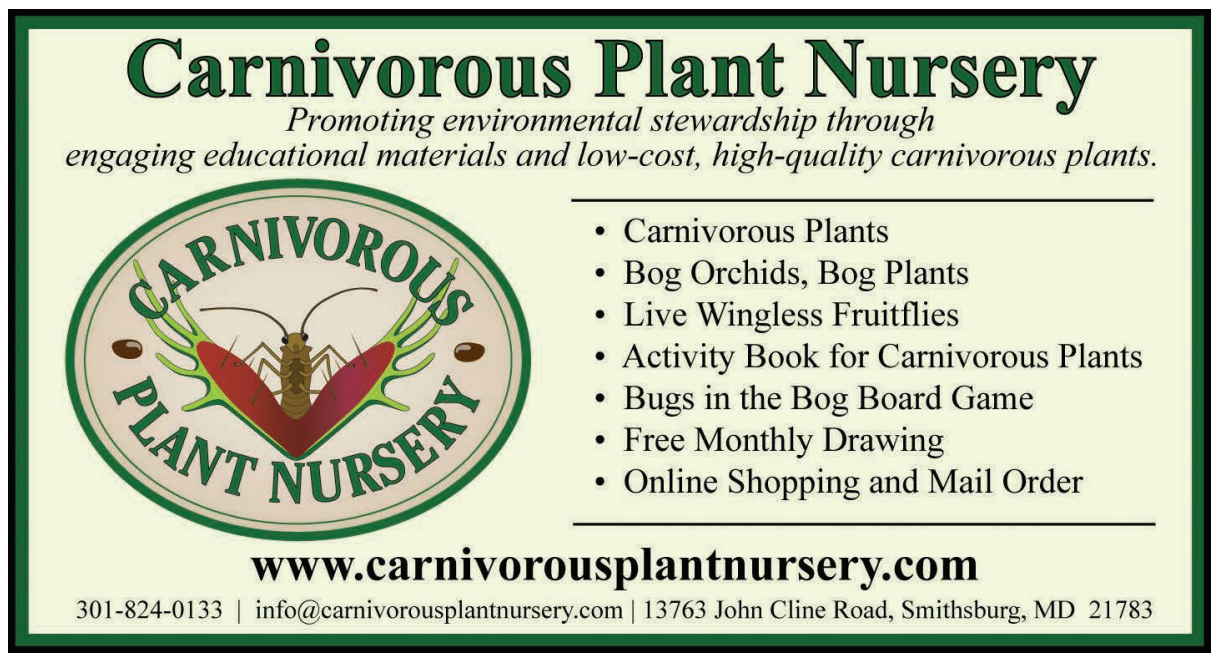




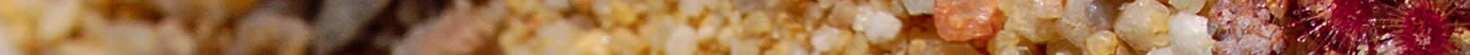
-

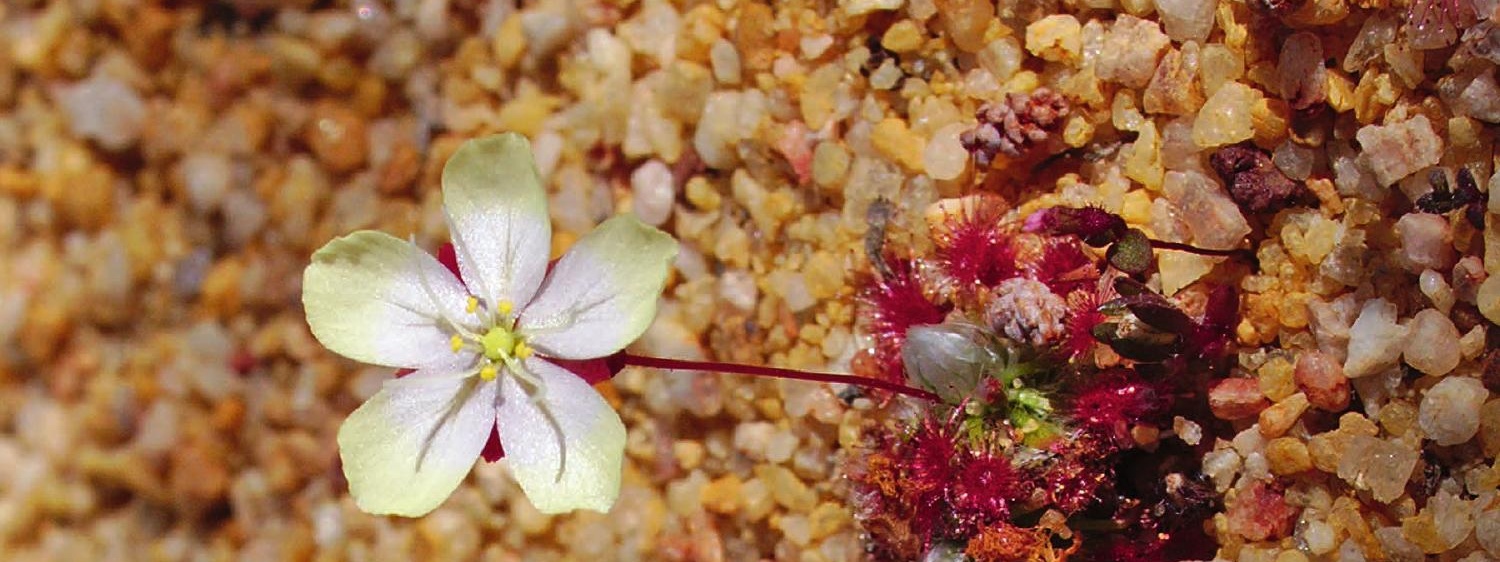

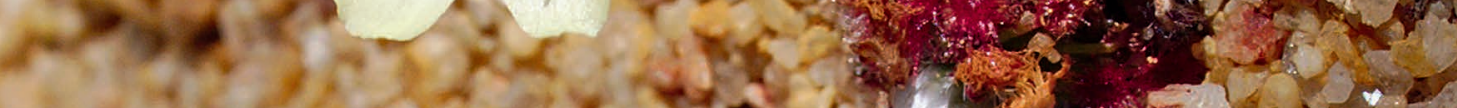

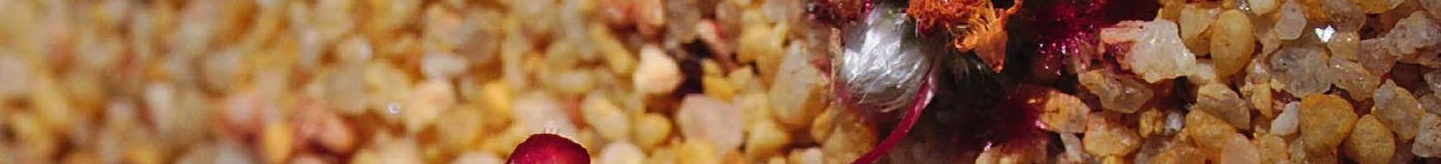

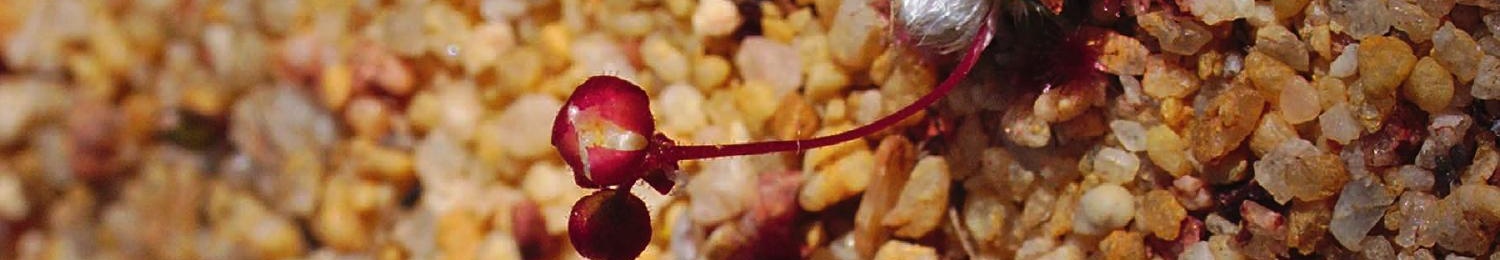
357 in

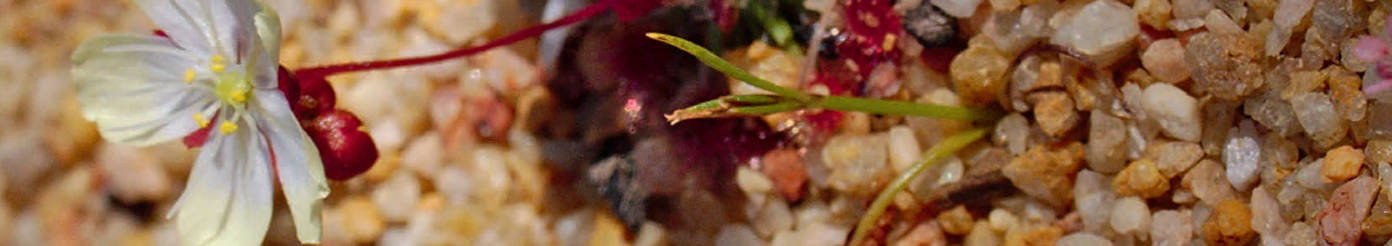

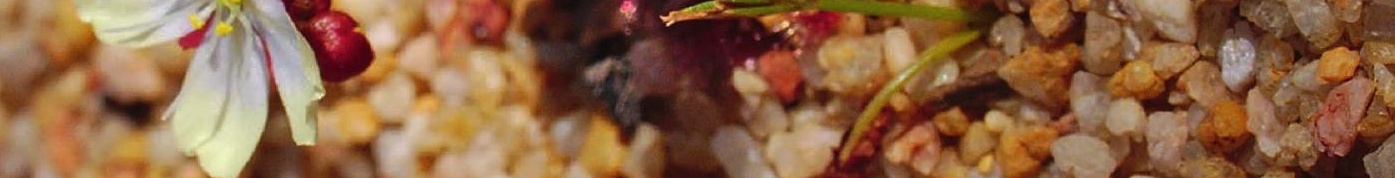

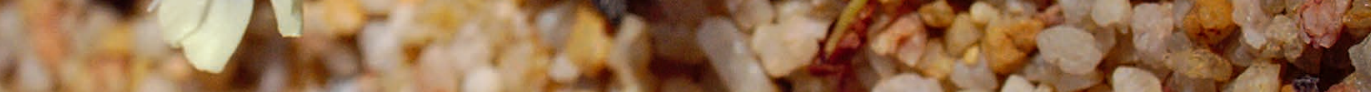

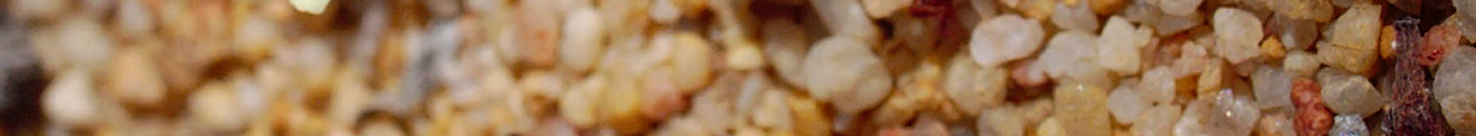

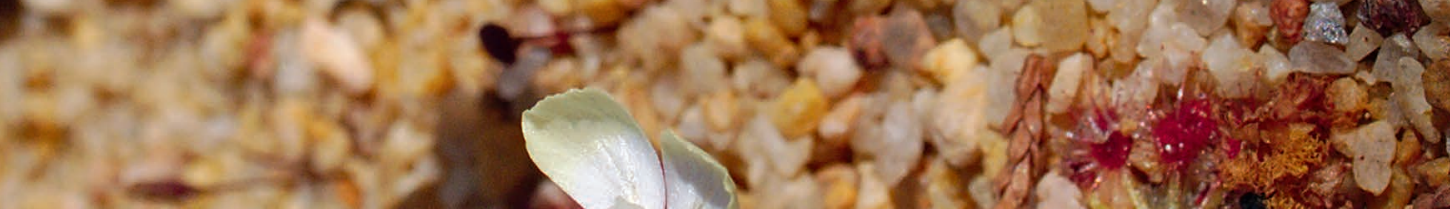

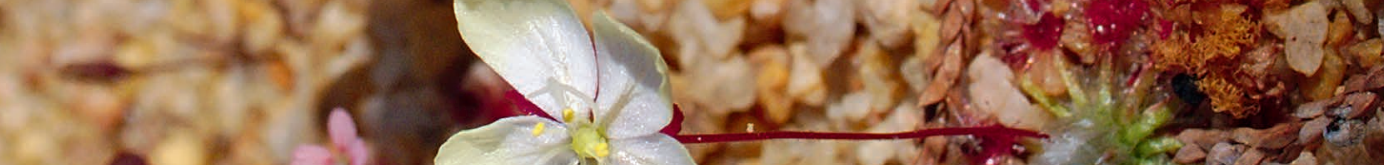
atis $\frac{n}{2 \cdot x^{2}}=$

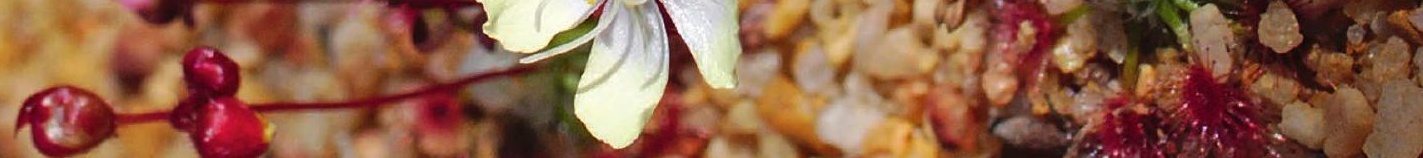

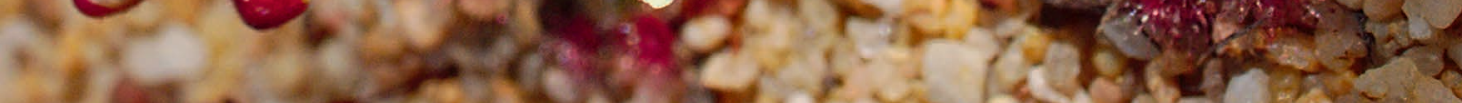

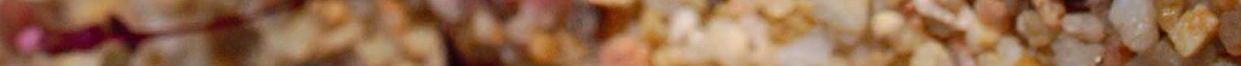

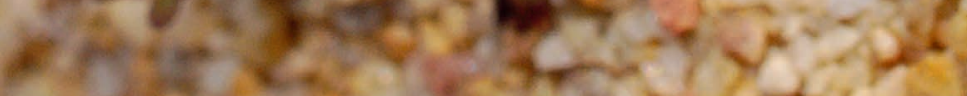
$x+2 y+3 x$ 


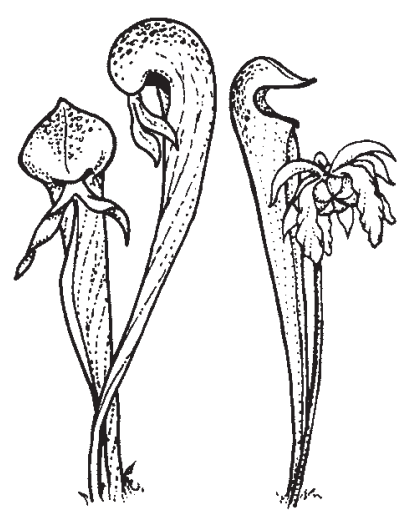

\section{CARNIVOROUS \\ PLANT \\ NEWSLETTER}

Journal of the International

Carnivorous Plant Society

www.carnivorousplants.org

\section{Volume 49, Number 1 March 2020}

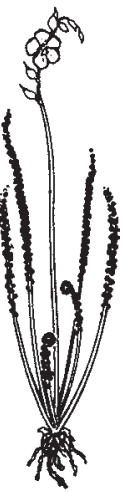

Front Cover: Traps of Genlisea hispidula growing through a plastic mesh. Photo by Rita Corino. Article on page 39.

Back Cover: Drosera coalara growing in yellow sand northeast of Badgingarra, Western Australia. Note the variability of style positions in the different flowers (left individual with upward-curved styles, middle with horizontal styles, right one somewhat in-between). Photo by Thilo Krueger. Article on page 6.

Carnivorous Plant Newsletter is dedicated to spreading knowledge and news related to carnivorous plants. Reader contributions are essential for this mission to be successful. Do not hesitate to contact the editors with information about your plants, conservation projects, field trips, or noteworthy events. Advertisers should contact the editors. Views expressed in this publication are those of the authors, not the editorial staff.

All correspondence regarding dues, address changes and missing issues should be sent to the Membership Coordinator at the ICPS. Do not send such correspondence to the editors. Checks for subscriptions should be made to the International Carnivorous Plant Society in US funds. Dues, including a subscription, are $\$ 30$ per year.

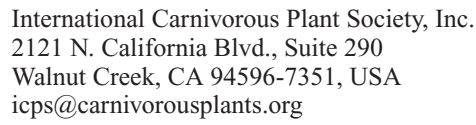

President

Vice President

Secretary

Treasurer

Board Member

Board Member

Board Member

Board Member

Membership Coordinator

Webmaster

Media Coordinator

Seed Bank Manager

CPN Editors

Managing Editor

Editor

Editor

Editor

Science Editor

Science Editor

Science Editor

\author{
Richard Nunn, richardnunn@carnivorousplants.org \\ John Brittnacher, john@carnivorousplants.org \\ Cindy Slezak, cindy@carnivorousplants.org \\ Daniela Ribbecke, daniela@carnivorousplants.org \\ Brent Jones, Conservation Director, brent@carnivorousplants.org \\ Kenny Coogan, Education Director, kenny@carnivorousplants.org \\ Jan Schlauer, Cultivar Registrar, jan@carnivorousplants.org \\ Bob Ziemer, bob@carnivorousplants.org \\ Cindy Slezak, cindy@carnivorousplants.org \\ John Brittnacher, john@carnivorousplants.org \\ Chad Williams, chad@carnivorousplants.org \\ Joe Griffin, joe@carnivorousplants.org \\ editor@carnivorousplants.org \\ Bob Ziemer \\ Barry Rice \\ Karl Herold \\ John Brittnacher \\ Andreas Fleischmann \\ Fernando Rivadavia \\ Jan Schlauer
}

Date of effective publication of the December 2019 issue of Carnivorous Plant Newsletter: November 8, 2019.

The ICPS is the International Cultivar Registration Authority (ICRA) for the names of cultivated carnivorous plants according to the International Code of Nomenclature for Cultivated Plants. Send relevant correspondence to the ICPS, Inc.

Carnivorous Plant Newsletter is published quarterly in March, June, September, and December by the ICPS, Inc., 2121 N. California Blvd., Suite 290, Walnut Creek, CA 94596, USA. Periodicals postage paid at Walnut Creek, CA and additional mailing offices. Postmaster: Send address changes to ICPS, Inc., 2121 N. California Blvd., Suite 290, Walnut Creek, CA 94596, USA. Printed by Allen Press, Inc., 810 E. 10th Street, Lawrence, KS 66044. Logo and masthead art: Paul Milauskas. (C) 2020 International Carnivorous Plant Society. All rights reserved. ISSN \#0190-9215 